of $35 \%$. Repeat coronary angiography before discharge showed a patent LAD coronary artery.

Fitzpatrick et al suggest that the improvement in rhythm control and haemodynamic status seen after IABP insertion was due to spontaneous re-opening of the infarctrelated vessel. Our observations confirm that patency of the infarct-related vessel may be associated with arrhythmia control. There have been no randomised trials of the value of emergency intervention in such circumstances. Nevertheless, it is clear that restoration of vessel patency by intracoronary thrombolysis, with or without angioplasty, may be a life-saving intervention in acute myocardial infarction complicated by ventricular arrhythmias that remain uncontrolled despite appropriate drug therapy

M HARGREAVES K CHANNON O ORMEROD Cardiology Department,
fohn Radcliffe Hospital, Oxford OX3 9DU

Lack of rebound during intermittent transdermal treatment with glyceryl trinitrate in patients with stable angina on background $\beta$ blocker

SIR,-Holdright et al in presenting their evidence of lack of rebound during intermittent transdermal treatment with glyceryl trinitrate in patients with stable angina on background $\beta$ blocker (British Heart fournal 1993;69:223-7) unfortunately left out one important limitation of their study. The rebound effect described in previous studies was seen in the exercise test in the morning after the patch had been removed the previous evening, ${ }^{1}$ or as an increase in numbers of attacks in the evening after removal of the patch worn during the day. ${ }^{2}$ In the daytime, patients generally spend their time upright and walking around, activities resulting in greater sympathetic activation and more hydrostatic pressure in the lower extremities than when the patch is worn at night when patients rest supine most of the time and are subject to low sympathetic activation. Parker et al showed that intermittent daytime patch administration of glyceryl trinitrate in young healthy volunteers was associated with increases in plasma catecholamines, plasma renin, and antidiuretic hormone. ${ }^{3}$ Such a mechanism may also operate in elderly patients, particularly as increasing age seems to be related to increased sensitivity to glyceryl trinitrate. ${ }^{4}$

Though Holdright et al's explanation that background $\beta$ blocker treatment was responsible for the absence of the rebound effect is quite plausible, it remains unproven until the same type of study has been performed with daytime application of the glyceryl trinitrate patch.

GUNNAR NYBERG Department of Medicine, Östra Hospital, Göteborg and Clinical Pharmacology, Astra Hässle, Mölndal, Sweden

1 DeMots H, Glasser SP. Intermittent transdermal nitroglycerin therapy in the treatment of chronic stable angina. $\mathcal{F} \mathrm{Am}$ Coll Cardiol 1989;13:786-93.

2 Ferratini M, Pirelli S, Merlini P, Silva P, Pollavani G. Intermittent transdermal nitroglycerin monotherapy in stable exerciseinduced angina: a comparison with a continuous schedule. Eur Heart $\mathcal{f} 1989 ; 10$ 998-1002.

3 Parker JD, Farrel B, Fenton T, Conamin MA Parker JO. Counter-regulatory responses to continuous and intermittent therapy with nitrolycerin. Circulation 1991;84:2336-45.

4 Cahalan MK, Hashimoto Y, Aizawa K Verotta D. Ionescu P, Balea M, et al. Elderly, conscious patients have an accentuated hypotensive response to nitroglycerin Anesthesiology 1992;77:646-55.

This letter was shown to the authors, who reply as follows:

SIR,-Dr Nyberg raises an interesting point about the mechanism of rebound associated with intermittent nitrate therapy. It is plausible that patch application at night resulted in less neurohumoral activation than would have occurred with daytime therapy. However, as we originally stated, ${ }^{1}$ we based the study design on the known circadian pattern of angina in order to maximise the likelihood of detecting rebound after patch removal. Exercise tests were performed in the morning to coincide with the wellrecognised morning peak of ischaemia. The benefits of such a schedule have to be weighed against the possibility that nocturnal patch application results in less sympathetic activity than daytime therapy. However, neurohumoral activation is only one mechanism that could be responsible for the rebound phenomenon. Other mechanisms that are independent of the timing of patch application include sulphydryl depletion, desensitisation of soluble guanylate cyclase, and plasma volume shifts related to altered capillary pressure. ${ }^{2}$

D R HOLDRIGHT R J KATZ C A WRIGHT JL SPARROW A K SULLIVAN A D CUNNINGHAM

Royal Brompton National Heart and Lung Hospital, Sydney Street,

1 Holdright DR, Katz RJ, Wright CA, Sparrow $\mathrm{JL}_{\mathrm{KM}}$, Sullivan AK, Cunningham AD, Fox KM. Lack of rebound during intermittent
transdermal treatment with glyceryl trinitrate in patients with stable angina on background $\beta$ blocker. Br Heart $\mathcal{f}$ 1993;69:223-7.

2 Needleman P, Johnson EM Jr. Mechanism of tolerance to organic nitrates. $\mathcal{F}$ Pharmacol Exp Ther 1987;184:7009-15.

3 Abrams J. Clinical aspects of nitrate tolerance. Eur Heart f 1991;12(Suppl E):42-52.

\section{Is there such a thing as normal sinus} rate?

SIR,-Although in his viewpoint Professor Meijler wrestled with the perpetually belaboured concept of "normal", he began: "The currently accepted limits for a normal (sic) sinus rate were set at 60 and 100 beats per minute by Kossmann in 1953". ' These limits were set long before 1953 in consecutive editions of the New York Heart Association's Nomenclature and Criteria in 1928 for "regular sinus rhythm" and subsequently in the 4th (1943) edition and thereafter for "normal sinus rhythm"2 at least partly because 60 beats per minute represents exactly five $200 \mathrm{~ms}$ boxes on ECG paper and 100 beats per minute represents three $200 \mathrm{~ms}$ boxes. Kossmann clearly described these limits as being chosen "for convenience and for uniformity of designation." In any event, in our paper we were not concerned with electrocardiography, but rather with clinical and epidemiological appropriateness. ${ }^{3}$

Professor Meijler referred to Murphy's seven definitions of normal. ${ }^{4}$ In a reply to the single letter that was critical of our work, I have already cited Murphy and have emphasised that our proposal of "normal" was as an operative definition in Murphy's sense of "acceptable"s (not noted by Professor Meijler). My colleagues and I understood that under conditions other than resting daytime ones individuals could indeed have sinus heart rates that are normal though beyond both of the operational (resting) limits that we proposed, as, for example, during sleep or during the range of physical activity. Moreover, if our paper were regarded as a redefinition of sinus tachycardia and bradycardia, the word "normal" could have been omitted from the title with no loss of message.

Professor Meijler challenges our study group (500 patients) as perhaps not being "a sufficiently large and appropriately stratified healthy sample". However, as we reported, our results accord with the results in the 5000 patients reported by the Framingham Heart Study. ${ }^{3}$ Moreover, a personal message from Professor Rauttaharju of EPICORE ((Cardiology) Epidemiology Coordinating and Research Centre) (Alberta, Canada) cites comparable results in over 18000 normal subjects. He has designed an abstract (now accepted) for our joint presentation at a forthcoming scientific meeting.

On the basis of past contributions Professor Meijler's views deserve respectful attention. However, in a survey of 136 distinguished members of the American College of Cardiology (many of them Professor Meijler's peers) over $90 \%$ agreed with the operational rate limits of 50 to 90 beats per minute with only two votes for the status quo and with the remainder supporting different variants. ${ }^{\circ}$

Professor Meijler refers to the increased cardiovascular mortality predicted by increased resting heart rates and asks "How important is the difference in mortality between patients with heart rates of 90 and 100 "? The answer awaits an appropriately designed and executed investigation. No formal investigation underlay the traditional 60 to 100 beats per minute range. Why then does Professor Meijler prefer this range to ours, which is based on the results of an appropriately designed study and are consistent with Framingham and EPICORE data? Indeed, so few subjects had rates between 90 and 100 beats per minute that there may, indeed, be a critical difference in that range.

In his last sentence Professor Meijler offers a truism-that is, trivial changes in "normal" boundaries irrespective of statistical significance may not reflect biologica significance. Yet, his very first sentence about "accepted limits" tacitly agrees that there can be conventional ("accepted") normal limits. In Professor Meijler's hospital do reports on electrocardiograms (computer generated or other) use "normal sinus rhythm" for regular sinus rhythms between 60 and 100 beats per minute and "sinus tachycardia" and "sinus bradycardia" for faster and slower rates?

Terminology greatly influences thought

patterns, because "linguistic usage shapes 
and reinforces selected cognitive tendencies". ${ }^{7}$ Both for scientific and practical usage when do we think "tachycardia" and think "bradycardia"? One is reminded of the early limits for sinus bradycardia induced by $\beta$ adrenoceptor blockers. As late as 1980 the rate target was set (by British Commonwealth authorities) at "under 70 beats per minute", 8 and until recently 60 beats per minute was the lower limit used by many physicians.

We studied people at rest in a familiar environment in the afternoon, typically when most physicians in the United States see most of their non-urgent office patients. Whatever the epidemiological data and statistical manipulations a rate in the $90 \mathrm{~s}$ in resting adult patients intuitively should be considered "fast" and I am certain that few physicians would be satisfied at any age were their own resting (not to say basal) daytime heart rates above 90

DAVID H SPODICK Cardiology Division Worcester MA 01604, USA

1 Meijler FL. Is there such a thing as a normal sinus rate? Br Heart $\mathcal{F}$ 1993;69:376.

2 Dolgin M. Normal sinus rhythm. Am $f$ Cardio 1993;71:496.

3 Spodick DH, Raju P, Bishop RL, Rifkin RD. Operational definition of normal sinus rate. Am f Cardiol 1992;69:1245-6.

4 Murphy EA. The logic of medicine. Baltimore: Johns Hopkins University Press; 1970:124-6.

5 Spodick DH. Normal sinus rhythm. Am $\mathfrak{f}$ Cardiol 1993;71:496-7.

6 Spodick DH. Survey of selected cardiologists for an operational definition of normal sinus heart rate. Am $\mathcal{Y}$ Cardiol 1993;72:487-8.

7 Frank, FW, Treichler PA. Language, gende and professional writing. New York and professional writing. New

8 Sloman JG, Manolas E. Cardiovascular disease. In: Avery GS, ed. Drug treatment. Principles and practice of clinical pharmacolog and therapeutics. 2nd ed. Sydney, Australia: Adis Press, 1980.

This letter was shown to the author, who replies as follows:

SIR,-The style and content of Dr Spodick's reaction to my Viewpoint show that he feels somewhat aggrieved that in the first place my opinion was asked and in the second that I tend to disagree with him on the importance of finding another operational definition of "normal" sinus rhythm. I regret this because in science a difference of opinion should be fun.

I remain unconvinced of the need for a change. This does not imply that I like a "normal" sinus rate of 60 to 100 beats per minute better than 50-90. I do not care unless it has been shown that one rate has more clinical relevance than the other or would improve our understanding of sinus node function in health and disease. Also no group of people-male or female; small or large; white or black; tall, small, or mixed-can represent all of mankind. Normality in Massachusetts, Halifax, or Framingham may not be the same in Holland, Nigeria, or Japan.

Finally I am not convinced by my peers in the American College of Cardiology that a change in defining the "normality" of sinus rate is important. In science two do not necessarily know more than one.

\section{BRITISH CARDIAC SOCIETY NEWSLETTER}

There was a good attendance at the European Society of Cardiology meeting in Nice at the end of August by members of the British Cardiac Society and one of the more unusual sights was Peter Sleight riding his English bicycle around the streets of Nice. Members expressed some concern bout the safety of such a strategy and it was a relief to see Peter Sleight travelling to London on the same aeroplane-particularly as he had just been invited to give the Thomas Lewis Lecture at our annual meeting in Torquay next year.

\section{British Cardiac Society Postgraduate} Advisor

Howard Swanton, who was appointed by Council to this post, is now seeing between two and four young cardiologists a month at SHO, registrar, or senior registrar level. $\mathrm{He}$ is happy to discuss career aspirations and career opportunities and will review CVs. As well as being on Council, Howard Swanton is on the Training and Manpower Committee and is well placed to offer career guidance. Appointments to see Howard Swanton can be made directly by telephoning 0713809055 .

\section{European Society of Cardiology}

Philip Poole-Wilson writes: The Congress of the European Society of Cardiology (ESC) for 1993 is over. About 10500 physicians or scientists attended the Congress and there were 4500 exhibitors or accompanying persons. The number of abstracts received was 6242 . Eight hundred and ninety abstracts were presented orally and 1026 as posters, giving an acceptance rate of $31 \%$. The weather was clement, the scientific programme excellent, the meeting was well attended, and several important new trials were reported. If you have comments or preferably suggestions to make about the meeting please do write either directly to S Nitter-Hauge (Chairman of the Executive Scientific Committee), to ECOR, or to Philip Poole-Wilson

During the General Assembly votes were taken on applications to join the ESC from the national societies of several countries. The ESC welcomed as new member countries: Russia, Moldavia, Georgia, Czech Republic, Slovak Republic, and the Ukraine.

On the Tuesday during the Congress the European Heart House was inaugurated. Land $\left(23000 \mathrm{~m}^{2}\right)$ was purchased at Sophia Antipolis in December 1991. Sophia Antipolis is about $15 \mathrm{~km}$ from the airport of Nice down the motorway in a westerly direction where traffic flow is lighter. The architect, Mr Jean Schmeltz, was appointed in May 1992 and the foundation stone was laid on 27 November 1992. The European Heart House was officially opened on 31 August 1993. The building is not finished but the outer structure is complete as are some of the main rooms. This will be a centre for many activities in cardiology. More information about the European
Heart House will appear in the newsletter in the next few months.

Please remember that the last date for the receipt of abstracts for the Congress next year in Berlin (9-14 September 1994) is 1 December 1993. The date has been brought forward for this one year only because the Congress is a joint Congress between the ESC and the ISFC (International Society and Federation of Cardiology). A large number of abstracts are expected and more time will be needed to process them because graders from all over the world will be used.

Medical standards of fitness to drive: Department of Transport

Michael Petch writes: Members of the Society will be aware of the guidelines published by the Department of Transport relating to driving and disorders of the cardiovascular system. These have been revised again recently and the new guidelines will be published in Health Trends. The guidelines are also available from the Medical Adviser, Medical Advisory Branch, Oldway Centre, Orchards Street, Swansea, SA99 1TU, and there is a publication for medical practitioners, entitled the $A t-a$ Glance Guide to the Current Medical Standards of Fitness to Drive which covers all aspects including the guidelines recommended by other panels-for example neurology.

There are important differences between the old and the new guidelines. The most important is that angiography is no longer required in the assessment of vocational drivers with coronary heart disease. Such drivers wishing to retain or regain their licence must remain free of symptoms, must not have had heart failure, and must be able to reach stage four of the Bruce protocol (not complete at least four stages as suggested in the Newsletter on page 204) "without symptoms or signs of cardiac dysfunction".

Other important practical differences include the acceptance of drivers with mechanical heart valves, provided that they remain in sinus rhythm and free from complications, and a relaxation of the guidelines relating to cardiac arrhythmias.

A final point is that members should be aware of a change in the nomenclature relating to vocational licences. The term Heavy Goods Vehicle (HGV) is now replaced by Large Goods Vehicle (LGV), and Public Service Vehicle (PSV) by Passenger Carrying Vehicle (PCV). These subtle changes may not matter to cardiologists but they are important for the transport industry.

\section{British Nuclear Cardiology Group}

Dudley Pennell, treasurer of BNCG writes: John Caplin of Hull is now president of the BNCG and the next annual meeting is to be held on 1 November 1993 at the National Heart and Lung Institute, Dovehouse Street, London SW3. There will be a guest speaker from the United States (Jeff Leppo, University of Massachusetts) who will be speaking on "Evaluation of myocardial perfusion and function with technetium based tracers". Other speakers include Dr Vallelely (tantalum radionuclide ventriculography), Dudley Pennell (pharmacological stress), Dr Underwood (hibernation), Dr Prvulovic (prognosis in coronary artery disease), Dr Lim (from group to individual risk) and Dr Norrell (the cardiologist's viewpoint). All cardiologists, nuclear physicians, and physicists are invited to attend. It 